\title{
Experimentally induced infections of European eel Anguilla anguilla with Anguillicola crassus (Nematoda, Dracunculoidea) and subsequent migration of larvae
}

\author{
O. L. M. Haenen ${ }^{1}$, L. Grisez ${ }^{2}$, D. De Charleroy ${ }^{2}$, C. Belpaire ${ }^{2}$, F. Ollevier $^{2}$ \\ ${ }^{1}$ Central Veterinary Institute, PO Box 65, $8200 \mathrm{AB}$ Lelystad, The Netherlands \\ ${ }^{2}$ Zoological Institute, Naamsestraat 59, Leuven 3000, Belgium
}

\begin{abstract}
Migration pattern of third-stage Anguillicola crassus larvae, and pathogenesis of the lesions induced by third-stage larvae, was investigated in European eel Anguilla anguilla L. Young elvers $(1 \mathrm{~g})$ were fed infected Paracyclops fimbriatus (Copepoda). Eel samples were collected and examined histologically at varying intervals during the 6 mo post-infection period. Third-stage larvae (L-III) migrated directly through the intestinal wall and body cavity to the swimbladder within $17 \mathrm{~h}$ postinfection. L-IV larvae were detected $3 \mathrm{mo}$ post-infection, and immature adults were detected within 4 mo post-infection. The parasites occasionally showed aberrant migration paths. Pathological effects caused by the parasite were less severe after experimentally induced infections than those detected in some natural infections.
\end{abstract}

\section{INTRODUCTION}

The parasitic nematode Anguillicola crassus (Kuwahara et al. 1974, Moravec \& Taraschewski 1988) originates from eastern Asia where it infects the Japanese eel Anguilla japonica, but does not cause serious pathological changes (Egusa 1979). In contrast to Japanese eels, European eels Anguilla anguilla L. develop pathological effects from $A$. crassus infections (Egusa 1979, Liewes \& Schaminee-Main 1987, van Banning \& Haenen 1989).

The life cycle of Anguillicola spp. in Japanese eels has been described by Egusa (1979) and Puqin \& Yuru (1980). The adult resides in the swimbladder lumen of the eel. After the female has copulated, the fertilized eggs are released through the vulva and, according to Egusa (1979), also by rupture of the female parasite. First-stage larvae (L-I) moult into second-stage larvae (L-II) while still within the egg. The eggs pass via the pneumatic duct through the digestive tract and out of the eel into the water. After hatching, the L-II larvae are eaten by copepods which serve as intermediate hosts. Inside the copepod the L-II larvae migrate to the haemocoel and moult into L-III larvae in $10 \mathrm{~d}$. When these copepods are eaten by eels the L-III larvae migrate through the wall of the digestive tract to the swimbladder wall, where, according to Puqin \& Yuru they moult into L-IV larvae 4 to 5 mo later. Immature adult and adult nematodes reside in the swimbladder lumen and feed actively on eel blood. The total life cycle of Anguillicola spp. in the Japanese eel has been estimated at 1 yr (Egusa 1979, Puqin \& Yuru 1980)

The life cycle of Anguillicola crassus in European eels was studied recently by De Charleroy et al. (1989), who demonstrated that, under optimal conditions, the life cycle of $A$. crassus in European eels takes less than $2 \mathrm{mo}$.

In 1980 Puqin \& Yuru proposed a direct migration route of third-stage larvae of Anguillicola globiceps through the intestinal wall and body cavity into the swimbladder wall of Japanese eel Anguilla japonica.

This report describes the migration of L-III larvae of Anguillicola crassus in the European eel and the pathological effects induced by these parasites in an experimentally induced infection.

\section{MATERIALS AND METHODS}

Eggs of Anguillicola crassus, containing L-II larvae, were collected from the swimbladder fluid of an infected eel. These eggs were released into fresh water 
at $20^{\circ} \mathrm{C}$, where they hatch within a few hours (De Charleroy et al. 1989). The intermediate host, the copepod Paracyclops fimbriatus, was cultured at $20^{\circ} \mathrm{C}$ in the laboratory and fed with the newly hatched L-II larvae (estimated equal numbers of larvae and copepods). The mean infection level of the copepods, after $9 \mathrm{~d}$ infection, was 1.2 larvae copepod-1 Three hundred unparasitised European elvers, each weighing ca $1 \mathrm{~g}$, were fed with the infected copepods (1 exposure of about 4 times as many copepods as eels). Afterwards, the elvers were kept in water at $20^{\circ} \mathrm{C}$ and fed with commercial pellet food, at a rate of $2 \%$ of body weight per day.

After this single infection, $60 \%$ of the eels were found to be infected with Anguillicola crassus larvae (infection level varying from 1 up to more than 20 larvae; dependent on the individual feeding behaviour of the eels).

At 28 different time intervals, samples of 10 eels were collected, anaesthetized and fixed in Bouin Hollande

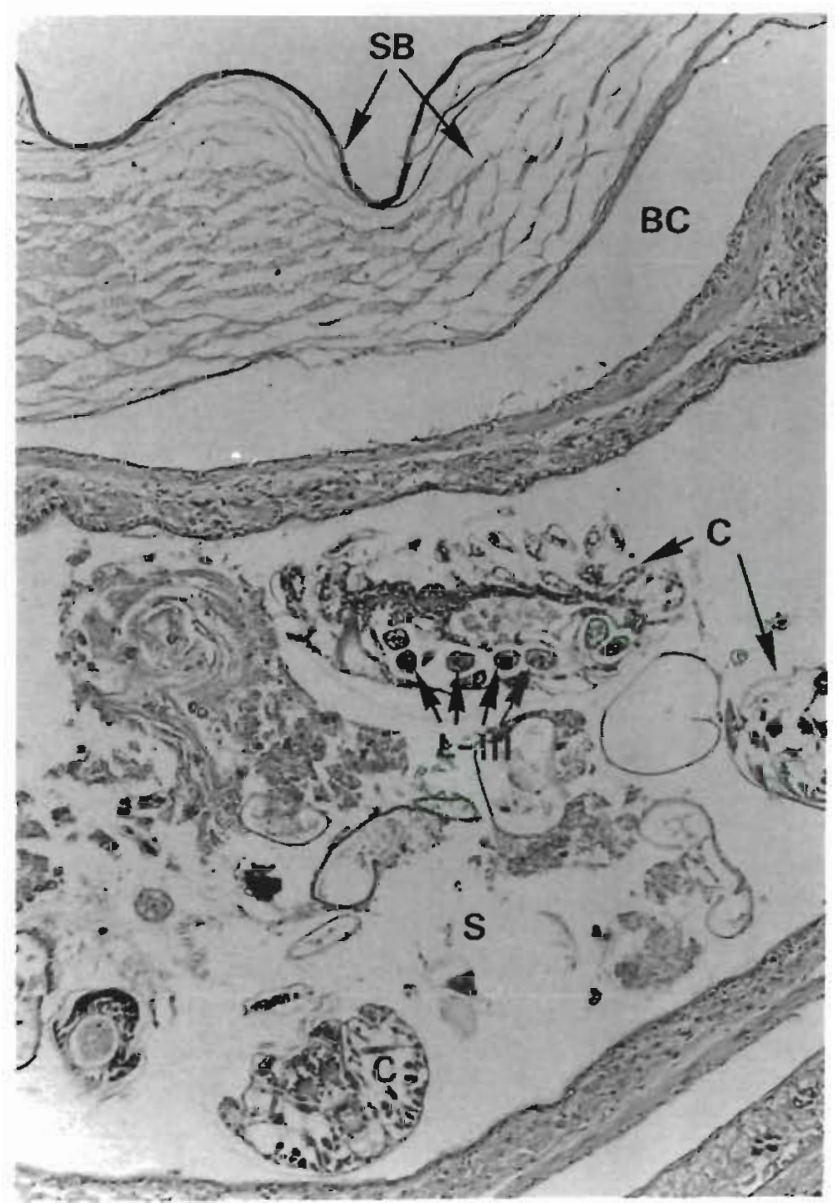

Fig. 1. Anguilla anguilla. Copepods (C) containing L-III larvae of Anguillicola crassus in the stomach (S) of eel, $1 \mathrm{~h}$ p.i. The swimbladder $(\mathrm{SB})$ is not yet infected. $\mathrm{BC}$ : body cavity. H\&E, $100 \times$, cross section for histological examination $(t=0$ and $1 \mathrm{~h}$ post-infection [p.i.]; every $4 \mathrm{~h}$ during the first $3 \mathrm{~d}$; at 4,7 and $8 \mathrm{~d}$ p.i.; and at 1, 2, 3, 4 and 6 mo p.i ). Histological sections of $4 \mu \mathrm{m}$ were stained with hematoxylin and eosin or trichrome, according to the method of Pollack (1944).

\section{RESULTS}

One hour after feeding the eels with the infected copepods, L-III larvae of Anguillicola crassus were detected in the stomachs of the eels. The swimbladder was still uninfected (Fig. 1). At 5 h p.i., L-III larvae were detected in the different layers of the digestive tract, especially in the submucosa, and in the body cavity. Tunnels were detected in the wall of the digestive tract (Fig. 2), as well as haemorrhages with numerous mononuclear phagocytes (Fig. 3). Until $17 \mathrm{~h}$ p.i. this situation did not change. At $17 \mathrm{~h}$ p.i., L-III larvae were detected for the first time in the swimbladder wall (Fig, 4); they

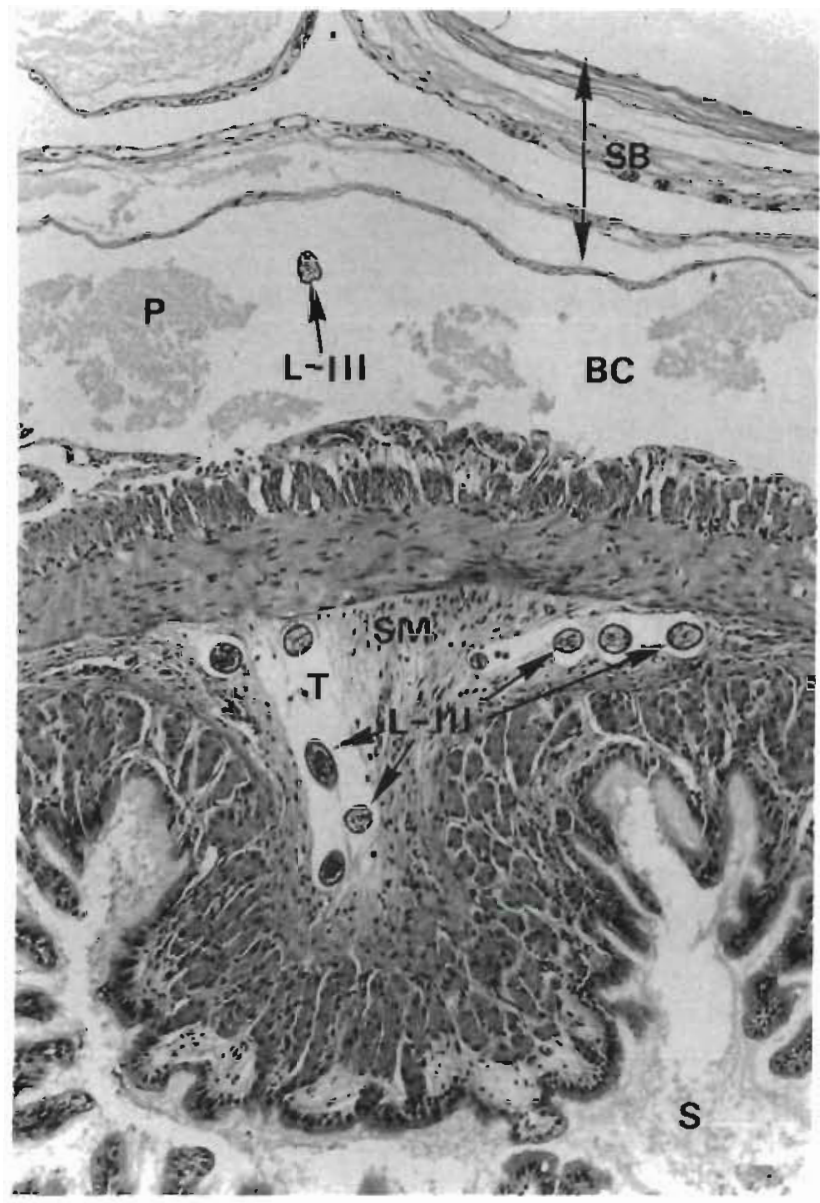

Fig. 2. Anguilla anguilla. L-III larvae of Anguillicola crassus migrating directly through the submucosa (SM) of the stomach (S) to the body cavity (BC) and causing tunnels (T). $5 \mathrm{~h}$ p.1. Protein (P), a sign of haemorrhages, is visible in the body cavity. The swimbladder (SB) is not yet infected. Trichrome, $100 \times$, cross section 
were situated in the subserosa and had not yet fed on eel erythrocytes. This situation remained unchanged until 3 mo p.i. At 3 mo p.i. L-IV larvae were detected for the first time, in the swimbladder wall; eel erythrocytes were detected within the parasite's intestine (Fig. 5). At 4 mo p.i. immature adults, full of eel erythrocytes and developing gonads, were detected within the swimbladder lumen (Fig. 6). At 6 mo p.i. this was again seen. No adult parasites were found at all. A summary of the results is given in Table 1. No pathological effects, such as inflammations or fibrosis of the swimbladder, were detected.

Occasionally, L-III Iarvae were detected migrating aberrantly, for instance in the ventral musculature (Fig. 7).

\section{DISCUSSION}

In this study the artificially induced infection of Anguilla anguilla with Anguillicola crassus was successful. We could detect the migration patterns of the parasitic larvae.

The $17 \mathrm{~h}$ period between feeding with infected copepods and the first appearance of L-III larvae in the swimbladder wall is remarkably short. The L-III larvae were detected mostly in the submucosa of the digestive tract, where they apparently reside some time before passing the denser muscularis. What attracts the larvae to the swimbladder is not known. Some larvae migrated aberrantly, but most of the L-III larvae migrated to the swimbladder.

L-IV larvae were detected in the swimbladder wall at 3 mo p.i., earlier than was reported for Japanese eels

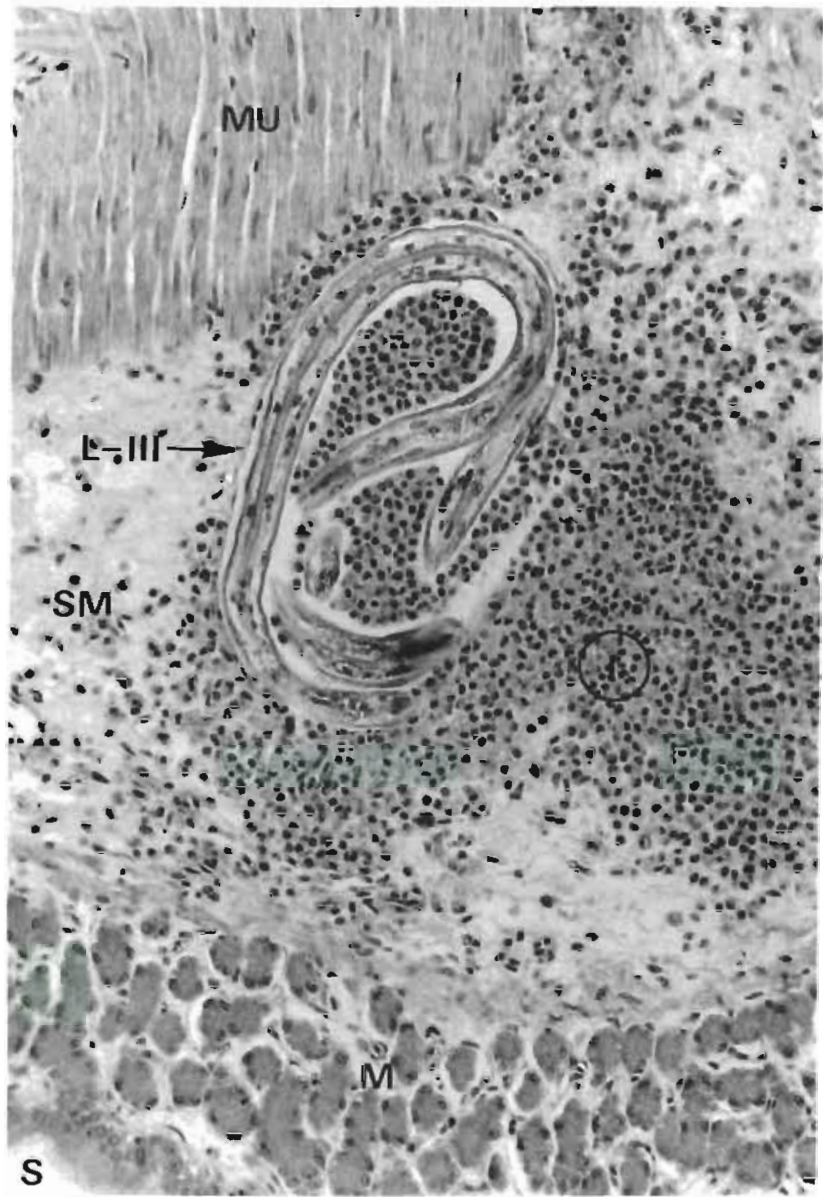

Fig. 3. Anguilla anguilla. Longitudinal section of L-III larvae of Anguillicola crassus situated in the submucosa (SM) of the eel stomach (S). Inflammatory cells (I) (mainly mononuclear phagocytes and erythrocytes) are visible. M: mucosa: MU muscularis. Trichrome, $200 \times$
Fig. 4. Anguilla anguilla. Longitudinal section of eel showing L-III larvae of Anguillicola crassus situated in the swimbladder subserosa (SS), 17 h p.i. M: mucosa; RM: rete mirabile, gas organ; SBL: swimbladder lumen; $\mathrm{BC}$ body cavity. Trichrome, $100 \times$

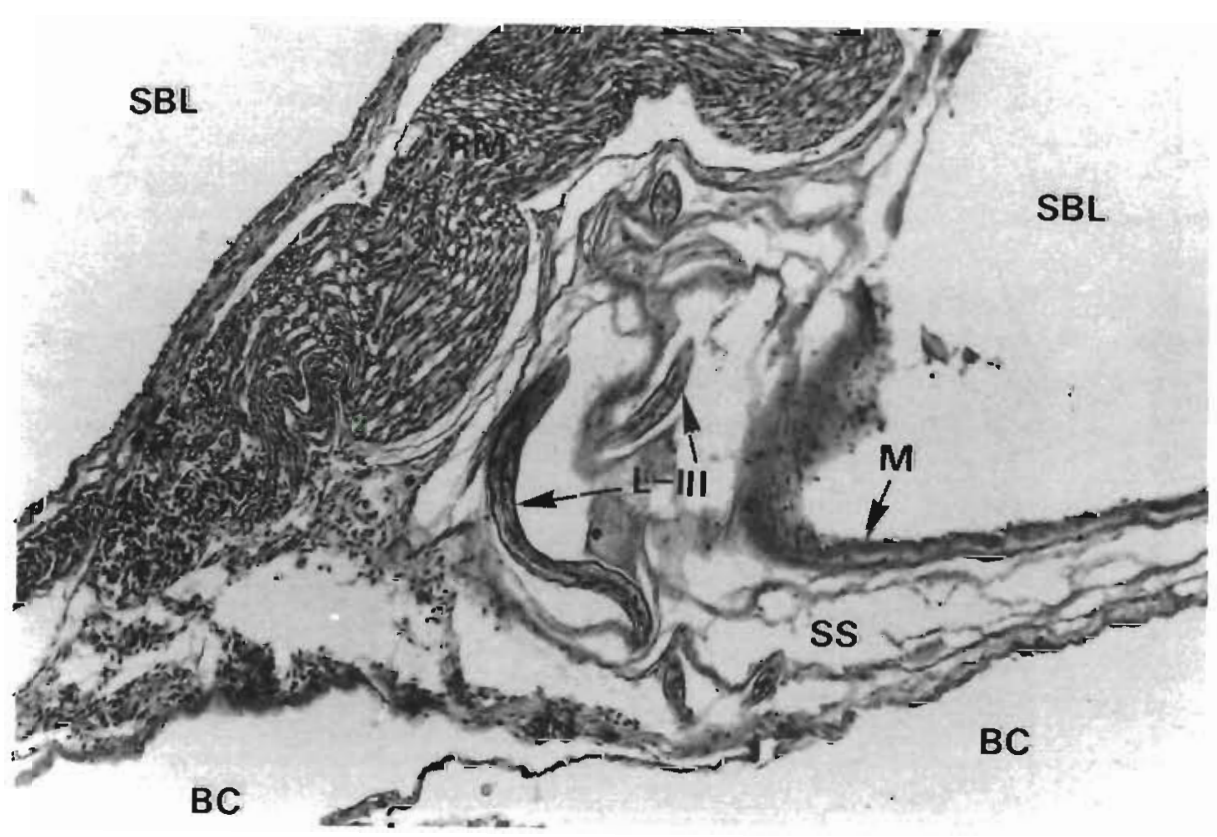




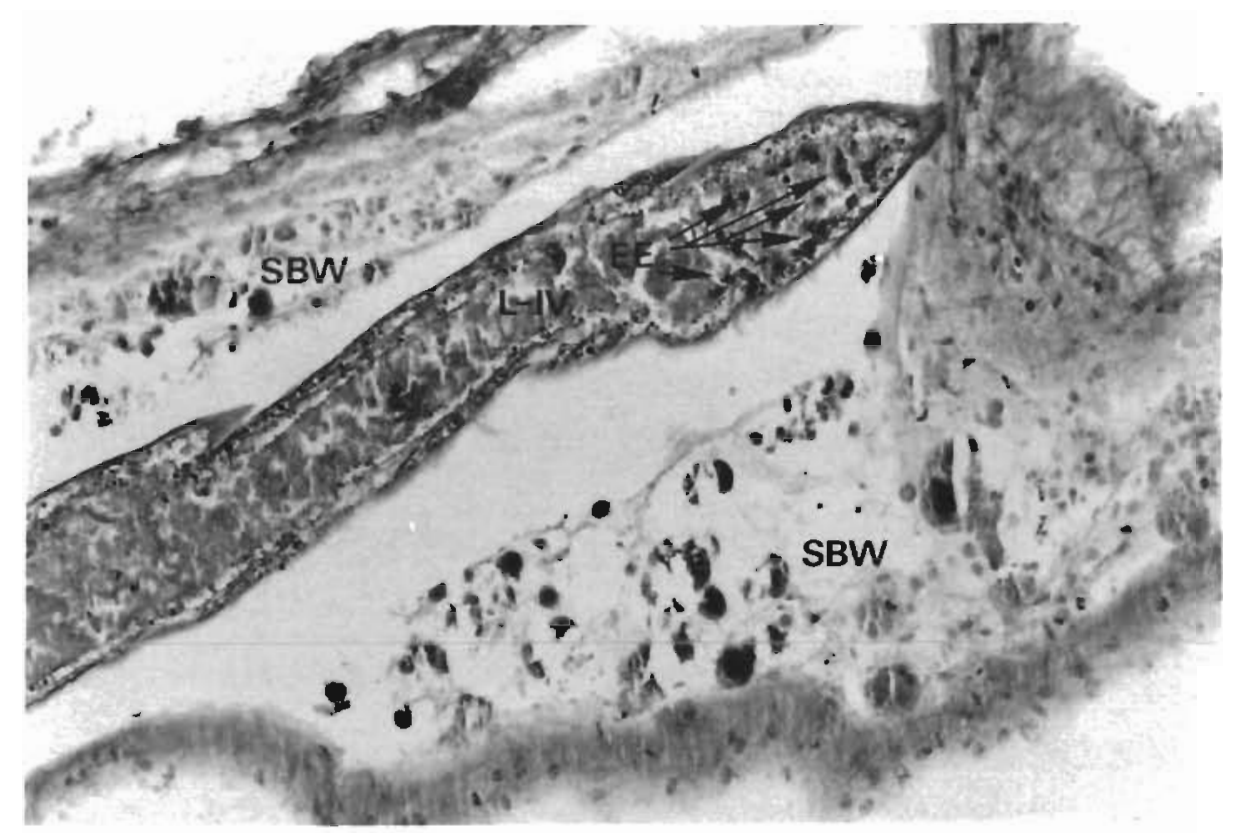

Fig. 5. Anguiija anguiiia. Detail of L-IV larva of Anguillicola crassus situated in the swimbladder wall (SBW), 3 mo p.i. Eel erythrocytes (EE) are visible within the parasite. Trichrome, $200 \times$

(Puqin \& Yuru 1980). These larvae had already been feeding on eel erythrocytes.

Since immature adults were detected in the swimbladder at 4 mo p.i., the life cycle of the nematode in European eels is considerably shorter than that described for Japanese eels (1 yr) (Egusa 1979, Puqin \& Yuru 1980). The life cycle seems longer however, than that reported for European eel by De Charleroy et al. (1989), of 2 mo. This is probably related to the different detection methods used in the experiments. De Charleroy et al. examined whole swimbladders of fresh eels for Anguillicola crassus, whereas we only examined a few histological sections. Therefore, eels in our experi- ments may actually have contained older larval stages at earlier times, which we missed.

Although we are aware of no reports that Anguillicola crassus migrates aberrantly in the Japanese eel, our study revealed that the nematode does on occasion migrate aberrantly in the European eel.

In a previous study of naturally occurring infections (van Banning \& Haenen 1989), we demonstrated that Anguillicola crassus caused pathological changes in eels. In contrast, the infections experimentally induced in the present study did not cause severe pathological changes. Fels living under natural conditions may be continuously exposed to nematode infections and thus

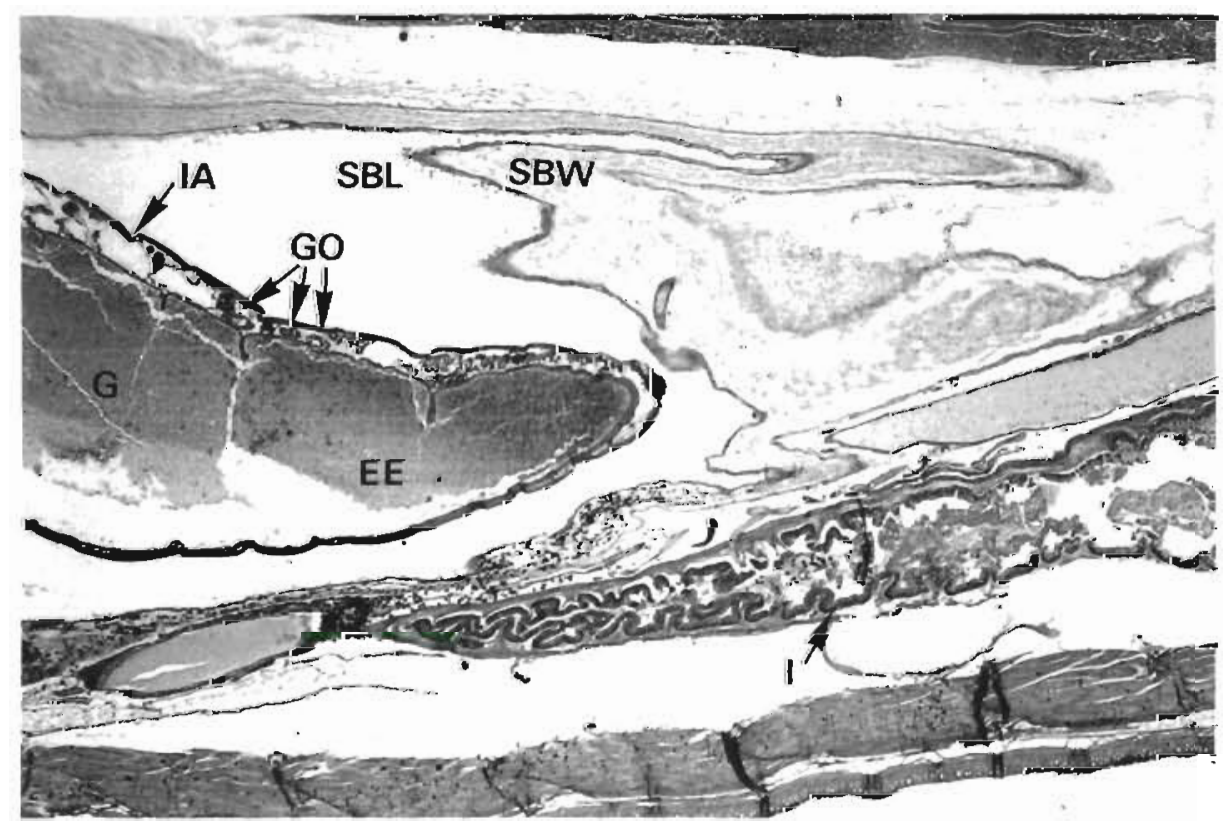

Fig. 6. Anguilla anguilla. Immature adults (IA) of Anguillicola crassus situated in the swimbladder lumen (SBL) of the eel, 4 mo p.i. The gut (G) of the parasite is filled with eel erythrocytes (EE). GO: Early development stage of gonads; SBW: swimbladder wall;

I: intestine. Trichrome, $20 \times$ 
Table 1. Anguillicola crassus in Anguilla anguilla. Location of parasite larvae in the European eel after experimentally induced infection

\begin{tabular}{|lccccc|}
\hline \multirow{2}{*}{ Location } & \multicolumn{5}{c}{ Time p.i. } \\
& 1 h & $5 \mathrm{~h}$ & $17 \mathrm{~h}$ & 3 mo & 4 mo \\
\hline Intestinal lumen & L-III & L-III & L-III & L-III & L-III \\
Intestinal wall & & L-III & L-III & L-III & L-III \\
Body cavity & & L-III & L-III & L-III & L-III \\
Swimbladder & & L-III & L-III & L-III \\
wall & & & & $\&$ L-IV & $\&$ L-IV \\
Swimbladder & & & & IA \\
lumen & & & & \\
IA: immature adult & & & & \\
\end{tabular}

may suffer more severe lesions than the experimentally infected eels, which were exposed only once to the parasites. Therefore, future studies on the pathological changes induced by $A$. crassus on European eels should include repeated experimentally induced infections.

\section{LITERATURE CITED}

Banning, P. van, Haenen, O. L. M. (1989). Effects of the swimbladder nematode Anguillicola crassus in wild and farmed eel Anguilla anguilla. In: Perkins, F. O. (ed.) Proceedings PAMAQ III-Conference, Gloucester Point, USA. Academic Press, New York, in press

De Charleroy, D., Grisez, L., Thomas, K., Belpaire, C. Ollevier, F. (1989). The life cycle of Anguilla crassa (Kuwahara, Niimi and Itagaki). Proceedings F.H.S./A.F.S. International Fish Health Conference, Vancouver J. Aquat. Anim. Health: (in press)

Egusa. S. (1979). Notes on the culture of the European eel (Anguilla anguilla) in Japanese eel farming ponds. In: Thurow F. (ed.) Eel research and management. Rapp. P.-v. Réun. Cons. int. Explor. Mer 174: 51-58

Kuwahara, A., Niimi, A., Itagaki, H. (1974). Studies on a nematode parasitic in the air bladder of the eel. I. Description of Anguillicola crassa n. sp. (Phimetridae, Anguillicolidae). Jap. J. Parasit. 23 (5): 275-279

Liewes, E. W. Schaminee-Main, S. (1987). Onderzoek naar de effecten van de parasiet Anguillicola crassa op de ontwikkeling van de paling (Anguilla anguilla) in een zout water

Responsible Subject Editor: Professor W. Körting, Hannover, F.R. Germany

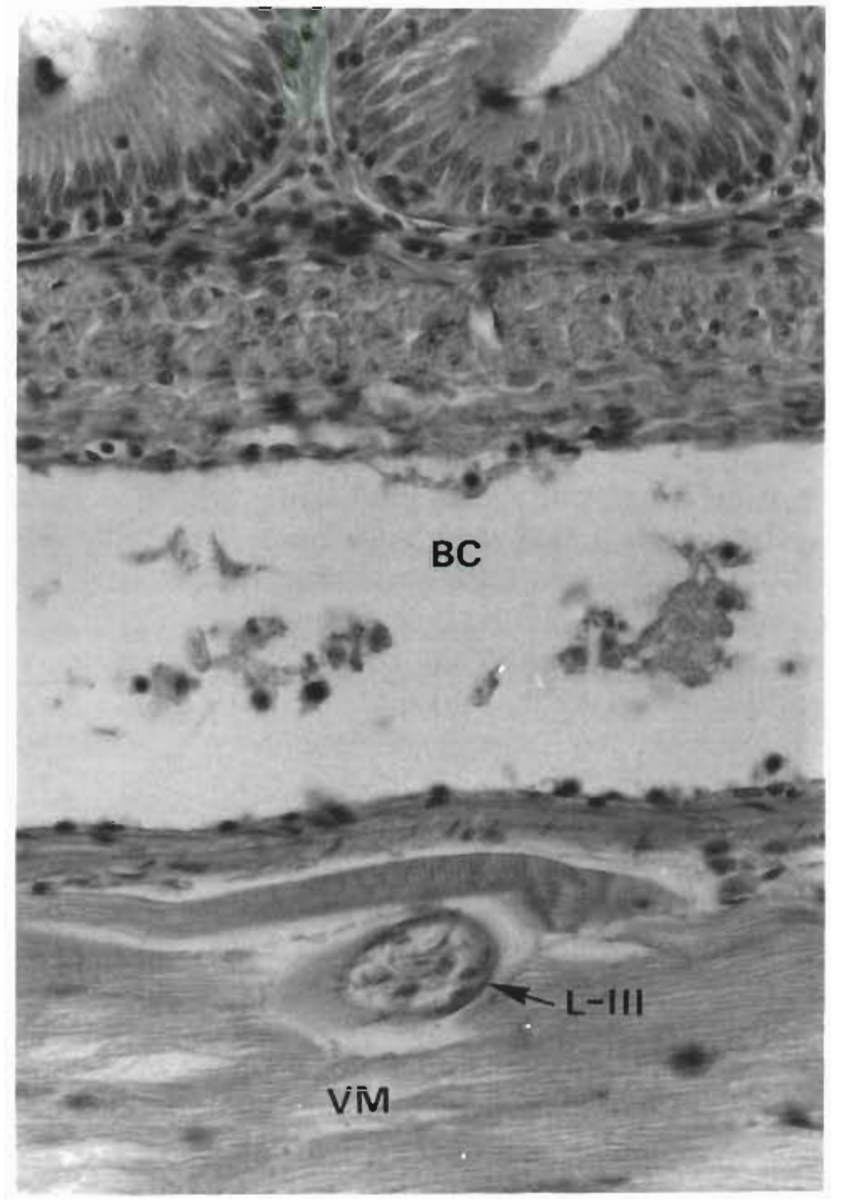

Fig. 7 Anguilla anguilla. L-Ill larva of Anguillicola crassus aberrantly migrating through the ventral musculature (VM) of the eel. BC: body cavity. H\&E, $400 \times$

palingmesterij. Internal report, Texvis B.V., Den Burg, Texel, The Netherlands

Moravec, F., Taraschewski, H. (1988). Revision of the genus Anguillicola Yamaguti, 1935 (Nematoda: Anguillicolidae) of the swimbladder of eels, including descriptions of two new species, A. novaezelandiae sp. n. and A. papernai sp n. Folia Parasitol. (Prague) 35: 125-146

Pollack, O. J. (1944). A rapid trichrome stain. Arch. Path., 37 294

Puqin, W. Yuru, Z. (1980). Observations on the life history of Anguillicola globiceps (Nematoda, Anguillicolidae). Acta zool. sin. 26: 243-249

Manuscript first received: January 27, 1989

Revised version accepted. August 1, 1989 